\title{
The Village Says "No": Why Online ADR is Not (Yet) Working in Rural India
}

\author{
John Clammer and Matthew Byrne \\ O. P. Jindal Global University, India
}

\begin{abstract}
This article argues that online dispute resolution (ODR) has not been readily accepted in India's rural hinterlands. This field study involved a trip to a "typical rural village" in North India with a population of approximately 3,000 people. Barriers to acceptance include IT literacy and connectivity, English language platforms and learning resources, reliance on and preference for village-based dispute-resolution systems, mistrust of external authority, lack of awareness of the benefits of ODR, and gender and cultural issues. We find that some villagers may be interested in ODR, but its adaption requires not only outlining the advantages of ODR but also creating a sense of ownership and managing resistance to outsiders. This could be done by providing training to groups likely to benefit from ODR, including youth, women, and NGOs. The case study also has theoretical implications for the study of comparative access to legal services, the relationship between concepts of rights and local concepts of morality, and for the persistence of social structure and "traditional" means of dispute resolution despite the possibility of access to "modern" forms of legal services.
\end{abstract}

Keywords: ADR; Alternative Dispute Resolution; India; Internet; ODR.

\section{Introduction}

The study of dispute resolution has a long pedigree in the anthropology of law. All known human societies inevitably generate conflicts and disputes over property, people, access to resources, and "rights"; however, these may be locally defined. Accordingly, every society must have mechanisms for attempting to resolve such disputes if it is to maintain itself over any extensive period of time. Indeed, even studies of small, contemporary "intentional communities" such as communes have shown that even in these social microcosms, clear and widely accepted principles and practices for conflict resolution must be present and transparently available to all members of the community. Among the reasons for the failure of many such social experiments is precisely that they did not have or failed to operationalize such forms of dispute resolution.

The anthropology of law has long recognized this, going back at least to classic studies of Llewellyn and Hoebel's earlier work in Cheyanne Way (1941). Likewise, it is implicit in almost every major ethnographic monograph, whether or not these are formally concerned with legal issues (e.g., see Evans-Pritchard's now classic studies of the Azande ${ }^{1}$ and Nuer ${ }^{2}$ peoples of Northeast Africa, where conceptions of rights over cattle and grazing rights in the latter are resolved through the medium of the "Leopard Skin Chief," so called because of his robe of office in the latter and the institution of witchcraft in the former). In his foundational text on the anthropology of law, Simon Roberts, in addition to documenting many ethnographic case studies, makes at least three important points: all societies experience disputes; all as a result have, from the perspective of contemporary ("modern") law, what may be seen as "alternative dispute resolution" (ADR) mechanisms; almost all recognize the fact that, unlike in modern large-scale and largely urban and industrial societies, disputes do not just disappear with their formal resolution, but leave long-lasting traces in the community concerned, especially when it is one in which people live in close and continuing proximity. ${ }^{3}$

\footnotetext{
${ }^{1}$ Evans-Pritchard, Witchcraft.

${ }^{2}$ Evans-Pritchard, Nuer.

${ }^{3}$ Roberts, Order and Dispute.
} 
This article is an exploration of a number of the issues posed by the anthropology of law by transposing them into the study of ADR, particularly in the form now emerging worldwide of online dispute resolution (ODR) in a North Indian village. However, the study is not simply a "test case" of mainstream anthropological ADR approaches, but takes cognizance of the fact that a number of important and new contextual factors must also be taken into account. In this case, these include the increasing penetration of mobile phone and to a lesser extent Internet technology into rural areas of India, and the general legal environment, which the average North Indian villager finds him or herself. This includes issues of cost, access to lawyers or arbitration panels, the glacial slowness of the Indian legal system (especially the courts), and the existence of widespread corruption. Behind this second issue lie more theoretical questions of the legacy of a colonial legal system not always adequately mapped onto the sociocultural realities "on the ground," growing attempts to "modernize" the Indian legal system and institutions by such means as increasing computerization for submitting documents and tracing the progress of cases, and the extent to which largely "Western" legal assumptions are made in attempts to describe the operation of dispute-resolution mechanisms that may in fact be based on very different unspoken principles derived from culture and religion.

Further, shortly after the fieldwork on which this article is based was completed, the COVID-19 pandemic began and soon spread in a massive way to India. The area in which the case village is located became a major "hot spot" of the coronavirus. The virtual paralysis of the Indian court system as a result almost immediately had local legal scholars debating the desirability of some form of ODR that could operate in the situation of closure of formal courts, extensive lockdowns (which prevented access to lawyers), and the necessity of maintaining "social distance" in legal situations as in others to prevent or slow the spread of the virus. Soon after the pandemic took hold (and India was one of the worst affected countries in the world), the School of Law at O.P. Jindal Global University (JGU) in Haryana, India - the law school to which the authors of this article both belong - held a webinar on exactly this subject. ${ }^{4}$

In what follows we discuss the current status of ADR in India and the legal instruments available for its potential implementation. We also report a detailed case study of a North Indian village to assess the potential acceptability of ADR and ODR and the relationship of these to existing and traditional dispute-resolution mechanisms. This empirical investigation raised a number of questions, which we then address. These include whether ADR would aid in empowering villagers by giving them dispute-resolution channels outside of the traditional mechanisms, which tend to be influenced by factors of age, gender, and caste. This is contingent on the successful penetration of the technology required to operate ODR - notably mobile smartphones and computers - and the ability to use the technology effectively. We then discuss the sociological structure of the village and its effect on technology use, and finally draw attention to a number of policy implications of the study, particularly the steps that would have to be taken to make any form of ADR a viable option for Indian villagers.

\section{The Indian Context}

India is a large place and even now its precise boundaries are contested. It can be divided not only into different states, languages, and ethnic groups, but also into different "legal realities." While a middle class "Delhi-ite" might be willing to go to court, the same may not be said for rural Indians still living outside of large urban centers. The growth of India's legal system including ODR is seen by many as having the potential to empower the rural masses and help India meet its "demographic dividend" by growing its economy and bringing the rural population into the IT dispute-resolution age. Almost $70 \%$ of Indians live in rural areas, and Indian citizens "have placed a significantly disproportionate reliance upon the traditional judicial system to resolve disputes." 5

India also has an estimated backlog of approximately 30 million court cases going back 30 years. ${ }^{6}$ There is also a shortage of judges and magistrates with one estimate being that India has only 19 judges for every one million people, ${ }^{7}$ with the judiciary facing a current shortage of 6,000 judges. Somewhat unsurprisingly with such an enormous backlog in place, the Supreme Court of India has embraced the idea of ADR, with Chief Justice Bobde recently stating that "[t]he length of time taken for conclusion of litigation is a big deterrent. It is therefore necessary to strengthen the use of ADR (such as through arbitration, mediation and conciliation), especially pre-litigation mediation." 8

Current ADR options available in India include arbitration, conciliation, mediation, court-managed ADR, Lok Adalat ("people's court"), and Panchayat (local legal and administrative units). India passed the Arbitration and Conciliation Act in

\footnotetext{
${ }^{4}$ See Kumar, "Arbitration, Mediation and Conciliation."

${ }^{5}$ Narain, "Legislative Framework," 77.

${ }^{6}$ Nair, "3.3 Crore Backlog."

${ }^{7}$ Press Trust of India, "Lakh People."

${ }^{8}$ The Telegraph, "CJI Focus," para. 3.
} 
1996 with plans to turn India into an arbitration hub. ${ }^{9}$ The country also signed the Singapore Convention on Mediation ${ }^{10}$ and amended both its Arbitration Act in 2018 and its Consumer Protection Act ${ }^{11}$ to include mediation and other ADR options.

In the infamous case of Guru Nanak, proceedings under India's previous Arbitration Act 1940 were described as something that:

made lawyers laugh and legal philosophers weep. Experience shows and law reports bear ample testimony that the proceedings under the Act have become highly technical accompanied by unending prolixity, at every stage providing a legal trap to the unwary. Informal forum chosen by the parties for expeditious disposal of their disputes has by the decisions of the Courts been clothed with "legalese" of unforeseeable complexity. ${ }^{12}$

To remedy this situation, India introduced its Arbitration and Conciliation Act in 1996 to bring India closer to the United Nations Commission on International Trade Law Model Law on International Commercial Arbitration. However, amendments to the new Act were made in 2015 and again by the Arbitration and Conciliation (Amendment) Act 2019 ("2019 Act"). Several judgments based on the new Act were overturned and no doubt created confusion in the eyes of arbitration bystanders. For example, in the 2002 case of Bhatia International v. Bulk Trading SA (2002), ${ }^{13}$ India's Supreme Court held that it had the power to grant interim orders even to arbitrations held outside of India. This was then overturned by the 2012 judgment in Bharat Aluminium Co. v. Kaiser Aluminium Technical Services Inc. (2012). ${ }^{14}$ Separately, India's 1986 Consumer Protection Act has been modified through the 2019 Consumer Protection Act. Unlike the 1986 Act, the 2019 Act allows courts to refer matters to mediation ${ }^{15}$ and the rules of direct selling have been extended to e-commerce. ${ }^{16}$

In the context of the rural sector, we note that existing studies of other villages in India suggested a number of reasons for failure in the uptake of ADR. This includes incompetence of ADR practitioners, unsuccessful precedent, traditional mindset, and lack of authority, in addition to negative public perception, lack of legal education, absence of quality training programs, and lawyer interests. ${ }^{17}$ The specific question in this case was whether these factors would also be reproduced in a detailed study of ADR in one North Indian village. Despite these reforms, our hypothesis remains that online ADR has not yet penetrated down to the village level.

\section{ADR/ODR: The Conceptual Framework}

To test the viability of ODR in the Indian context and to attempt to assess responses to the possibility of utilizing such alternative methods in the context of the vast rural hinterlands of India-rather than in urban areas where access to courts, legal advice, lawyers, and information is much more accessible in principle - it was decided to explore the knowledge and potential reception of ADR in a village community reasonably close to the university from which the study was carried out. While there is no such thing as a truly "representative" village in a country as large as India, with its enormous environmental variety and cultural and linguistic differences, it was expected that a detailed study of even a single sample village would at the very least establish the parameters for future and broader-based studies of the reception of ADR in rural India. The case study village will be referred to throughout the study by the fictional name of "Dispute Resolution Village X" to disguise its specific identity.

Before plunging into the village, some additional context is necessary. Accordingly, we begin by looking at current online ADR options available in India, as well as mobile phone and Internet penetration. We also look at the availability of online ADR to Indian consumers, case law, judicial precedent, and commentary, among other matters.

\section{Methodology}

The field research was carried out from August to December 2019 by a team of students directed by two senior faculty members (one of whom co-authored this article) from the School of Liberal Arts and Humanities at O.P. JGU in Haryana, India. The students (24 in total) were divided into research teams, each responsible for one area of the project. They were required to devise interview schedules appropriate to the particular group that they were researching (e.g., women, staff of the village

\footnotetext{
${ }^{9}$ Pahwa, "Making India an Arbitration Hub."

${ }^{10}$ Rodrigues, "Reintroducing Mediation to Millennial India."

${ }^{11}$ Singh, "Consumer Protection Act."

${ }^{12}$ Guru Nanak Foundation v. Rattan Singh \& Sons (1981) AIR 2075, (1982) SCR (1) 842.

${ }^{13}$ Bhatia International v. Bulk Trading SA (2002) 4 SCC 105.

${ }^{14}$ Bharat Aluminium Co v. Kaiser Aluminium Technical (2012) 9 SCC 552.

${ }^{15}$ Consumer Protection Act 2019, s 37(I).

${ }^{16}$ Consumer Protection Act 2019, s 94.

${ }^{17}$ Muhamad, Alternative Dispute Resolution.
} 
schools, farmers, shopkeepers, members of the local political structures). The research was carried out through semi-structured interviews, participant observation, and mapping objective data from the national census and other sources onto the actual "onthe-ground" reality of the village (factors such as caste and occupations). Also included were group discussions with village leaders and with the principal of the village government elementary and junior high school. The background to this was a thorough prior collective analysis of the census and the local histories and material available from the local bank and Panchayat records. On completion of interviews spread over the research period, all data were collated and presented in group sessions both during and after the research project, and refined and edited according to feedback and mutual sharing of insight.

No participants were given any incentives monetary or otherwise to participate, and no participant was denied any level of involvement in sharing their opinions or ideas. Participants were free to give or withhold their names, as they desired. Most chose to freely share their identities and, in the case of village leaders, both members of the Panchayat and leaders of farmers' groups, their names were naturally known and no anonymity was expected. In the few cases when individuals did not wish their identity to be known, this stipulation was strictly followed.

All members of the village community were aware of the study and for the most part were eager to have their voices heard. The study was carried out with the full permission and knowledge of the Panchayat head, the leader of the farmers' association, and the principal of the village school. JGU has built a close relationship with the village over several years, as students have gone there as volunteers to help in the elementary school and the government kindergarten; the university is now known to the villagers by way of this relationship. Further prior consultation was undertaken by the co-author of this article and his colleague (a human geographer) with village elders to gain their agreement and active cooperation before the research was initiated. The field portions of the research were undertaken wholly in Hindi, the language of the district, to avoid any problems of miscommunication or poor translation. At the time of the research, JGU did not operate a research ethics system. However, the research was undertaken in full knowledge of and compliance with the Human Research Ethics standards, and following the fieldwork ethics protocols of the American Anthropological Association.

We were concerned to discover whether online ADR empowers villagers by resolving their disputes outside the traditional village-based ADR system and brings with it many benefits; whether this possibility was little known, subordinated to the traditional methods of dispute resolution; or whether it was known but technologically difficult to access. In principle, ADR brings with it multiple potential benefits such as early resolution, confidentiality, finality, binding orders, party autonomy, costeffectiveness, neutrality, and a single procedure, among other benefits. ${ }^{18}$ In light of India's courts backlog, online ADR could, in theory, simply be an extension of existing ADR methodologies leveraging the Internet and mobile smartphone penetration to increase the efficiency of ADR toward India's rural masses.

Second, in reference to our village case study, it should be noted that there might be distrust not only of the Indian courts but also of mediators themselves. According to Nairan and Sankaranarayanan:

most mediators believe there exists a palpable mistrust of the process of mediation from within the litigants as well as the legal fraternity. While a wide variety of reasons are considered responsible for the same, lack of awareness is the primary concern. ${ }^{19}$

To even begin to assess the potential viability of ADR and especially of ODR, not only are such attitudinal factors in need of further investigation, but also are objective ones such as access to the technology that makes ODR even theoretically possible. A review of various online ADR providers finds that some webpages are in English with no material apparently provided in either written or audiovisual Hindi. The Haryana State Legal Services Authority provides an online brochure on ADR, again in English. ${ }^{20}$ The major language throughout the study area - and, indeed, across the whole of North India—is Hindi, and English (if spoken at all) is largely the preserve of the better educated who have had the opportunity to attend an English medium school.

The National Law School of India offers an online Consumer National Mediation Centre, ${ }^{21}$ also recognized by the Ministry of Law and Justice. Online arbitration, mediation, and conciliation services are also offered by a multitude of service providers. ${ }^{22}$ Further, the Indian National Government Portal provides links to numerous ADR services as diverse as railway claims, tax settlement, human rights, and consumer protection webpages. ${ }^{23}$ Elsewhere, students from West Bengal won India's first "E-

\footnotetext{
${ }^{18}$ World Intellectual Property Organization, “ADR Advantages.”

${ }^{19}$ Nairan, "Legislative Framework," 113.

${ }^{20}$ Vazifdar, "Foreword."

${ }^{21}$ National Law School of India, "Online Consumer Mediation Centre."

${ }^{22}$ Legal Referee, "Services: Arbitration."

${ }^{23}$ National Portal of India, "Alternative Dispute Redressal."
} 
Alternate Dispute Resolution Challenge" in 2019 to build an ADR platform, creating an online mediation platform with more than 100 mediators and locations across India. ${ }^{24}$

This article does not delve in great detail into the legal recognition of online arbitration/ADR but notes that Section 4 of the Information Technology Act 2000 allows agreements to be in electronic form. Nevertheless, it appears that online ADR including arbitration, conciliation, and mediation is an option available to Indians with Internet access.

\section{ADR in India and Beyond: A Brief Review}

The Arbitration and Conciliation Act provides for ADR platforms of arbitration, conciliation, mediation, Lok Adalat, and judicial settlement. Arbitration may be described as the quick, just, and binding determination of a dispute. It involves the use of a third party (the arbitrator) or a panel of arbitrators to issue a binding award that has effect as a court order and is covered under Sections 1 to 60 of the Arbitration Act. Arbitrators make binding decisions on parties that are essentially a ruling on the party's rights and who "wins."

Contrary to this is mediation, whereby the parties can choose a mediator who can assist the parties to resolve the matters themselves. Mediation is not binding without a party's consent, and a mediator does not act in either party's best interests. A mediation agreement may also be binding and have the force of law but it does not involve a mediator making a ruling or determination on a party's "rights" as such. Meanwhile, conciliation involves use of a third party who may propose a settlement agreement, liaise with both parties, and whose appointment does not require prior agreement. Conversely, neutral evaluation involves a neutral third party hearing the disputants' cases before providing them with their evaluation of the dispute.

"Lok Adalat" is described as a "a forum where disputes/cases pending in the court of law or at pre-litigation stage are settled/compromised amicably. Lok Adalats ["Peoples Courts"] have been given statutory status under the Legal Services Authorities Act, 1987." "Mobile Lok Adalats" involve travelling to different parts of the country to resolve disputes. According to the National Legal Services Authority of India, these had resolved more than 80 million disputes by $2015{ }^{26}$

The Indian Economic Service webpage describes Gram Nyayalayas as:

mobile village courts in India established under the Gram Nyayalayas Act, 2008 for speedy and easy access to [the] justice system in the rural areas of India. They are aimed at providing inexpensive justice to people in rural areas at their doorsteps. The Act came into force on October 2, 2009. Gram Nyayalaya is a mobile court and exercises the powers of both Criminal and Civil Courts; i.e., the seat of the Gram Nyayalaya will be located at the headquarters of the intermediate Panchayat, but they will go to villages, work there and dispose of the cases. It can try criminal cases, civil suits, claims or disputes which are specified in the First Schedule and the Second Schedule to the Gram Nyayalaya Act and the scope of these cases can be amended by the Central as well as the State Governments, as per their respective legislative competence. ${ }^{27}$

That said, not all matters can be resolved by a particular ADR method. For example, matrimonial disputes are generally not arbitrable but may be settled by mediation. In India different legal systems apply for Hindus and Muslims. The Hindu Marriage Act 1955 is different in scope from parallel legislation, covering Muslim marriage and inheritance, and similar specific provisions apply to other religious minorities such as Christians, Parsis, and Jains.

Fully automated services in the United States (US) such as Cybersettle allow parties to resolve monetary disputes confidentially through an automated process. According to the company's website:

contending parties submit confidential offers and demands on-line from most computers, smart phones or tablets. Cybersettle instantly compares the parties' submissions to determine if they are in range of a mutually-acceptable settlement. If not, it prompts the parties to submit their next offer. If yes, the parties arrange payment. Neither party sees the other party's offer or demands (double-blind) unless and until a settlement is reached. ${ }^{28}$

Unfortunately, many of these online services are in English and are primarily based in the US. Other advantages include that the Internet is a neutral place for parties to negotiate or meet, that arbitration submissions, for example, could be received at any time, and parties can work on their matter online or offline.

\footnotetext{
${ }^{24}$ Student Judicial Association, "NUJS Startup."

${ }^{25}$ National Legal Services Authority, "Lok Adalat."

${ }^{26}$ National Legal Services Authority, "Lok Adalat."

${ }^{27}$ Indian Economic Service, "Gram Nyayalayas or Village Courts."

${ }^{28}$ See http://www.cybersettle.com
} 


\section{Accessing ADR: Internet and Mobile Phone Penetration in India}

India is estimated to have the second highest number of Internet users after China, ${ }^{29}$ with about $36 \%$ of the population having Internet access. As shown in Figure 1, mobile phone penetration is even higher and is estimated to be approximately 85-90\% of the 900 million Indian "subscriber ceiling" (i.e., excluding those who cannot buy a mobile phone due to their age or income)..$^{30}$

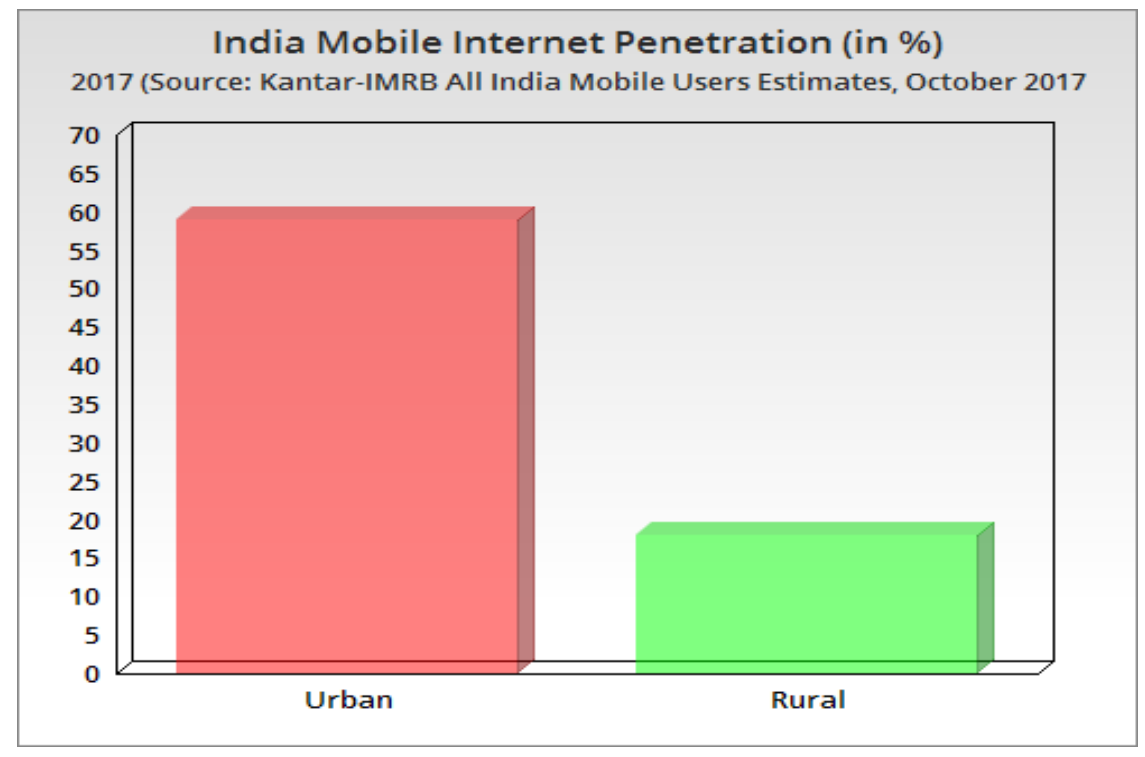

Figure 1. India mobile Internet penetration as a percentage.

Internet access also needs to be seen in light of various demographics, including that $67 \%$ of Indian Internet users are male ${ }^{31}$ and $57 \%$ of rural users are aged under 25 . Likewise, $60 \%$ of rural Internet users were estimated to use their mobile Internet for entertainment purposes, $15 \%$ for online finance transactions, and only $14 \%$ for other services. This contrasts with the figures $82 \%, 42 \%$, and $36 \%$ for urban dwellers in 2017 (see Figure 2). ${ }^{32}$ Such access and the stability of Internet and mobile phone usage is clearly a critical prerequisite for utilizing online ADR with any degree of confidence. Yet, what the figures also show is that for rural populations, except for emergency purposes, mobile usage is heavily biased toward entertainment. We would suggest, if possible, that ODR platforms might be more marketable to the rural masses if they were delivered in a way that made learning entertaining.

\footnotetext{
${ }^{29}$ Mandavia, "Internet Users."

${ }^{30}$ Khatria, "Saturation Point."

${ }^{31}$ Indo-Asian News Service, "Internet Users in India."

32 Internet and Mobile Association of India, 2017 Mobile Internet Report.
} 


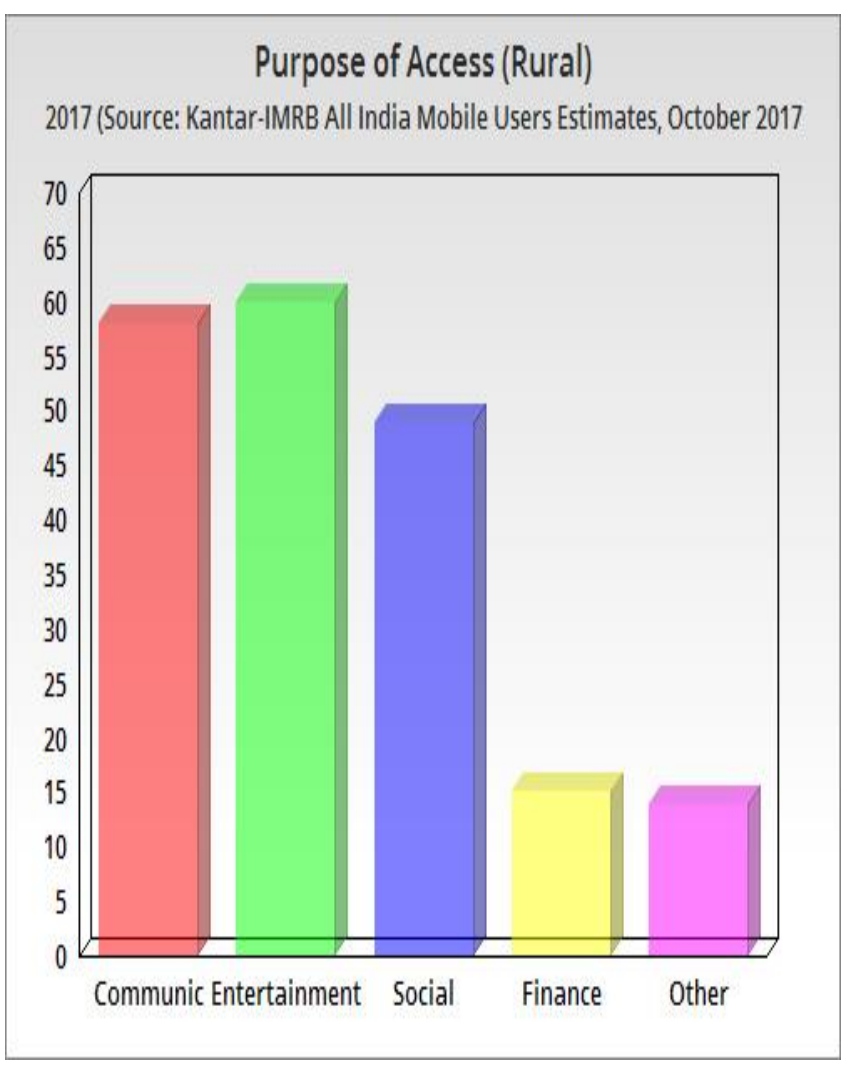

Figure 2. Reasons for accessing Internet via. mobile phones.

Despite a plethora of speeches, webpages, and online availability of ADR mechanisms, coupled with increasing Internet and mobile accessibility in urban and rural areas, a combination of cultural, demographic, and technical factors are inhibiting the uptake of online ADR at the village level. We decided to investigate a representative North Indian village to test the knowledge and actual usage of (if any) online ADR processes and facilities.

\section{The Village Case Study}

India is a very large country and ecological conditions (and, hence, local economies), social structures, religious composition, and other factors vary substantially across the area. Naturally, these and other factors such as proximity to a larger town, transport links, and access to electricity significantly influence the probability or possibility of any given village having access to any form of ODR mechanisms. While urban communities have far greater opportunities for this-given the availability of broadband Internet access, relatively reliable electricity supply, higher likelihood of knowledge of computer usage, and more diverse and fluid social structures (and, of course, proximity to formal legal institutions) - rural communities, which still constitute a large proportion of India's population, are likely to be both relatively disadvantaged technologically and to have other, more traditional, means of dispute resolution. While obviously not implying that any one village can possibly be representative of rural India, this research, designed to discover at least in outline knowledge or use of ODR mechanisms, is based on an in-depth study of one village situated in an accessible location in relation to the university where the research was carried out.

The following is a description of the village, its social structure and economy, its use of IT-enabled functions (including but not limited to ADR), and a discussion of the nature and forms of dispute resolution practiced in the village. As noted, the research was carried out over a four-month period (August to November 2019), utilizing a group of students from JGU under the direction of one of the principle researchers and authors of this article, who is an experienced sociologist and ethnographer. 


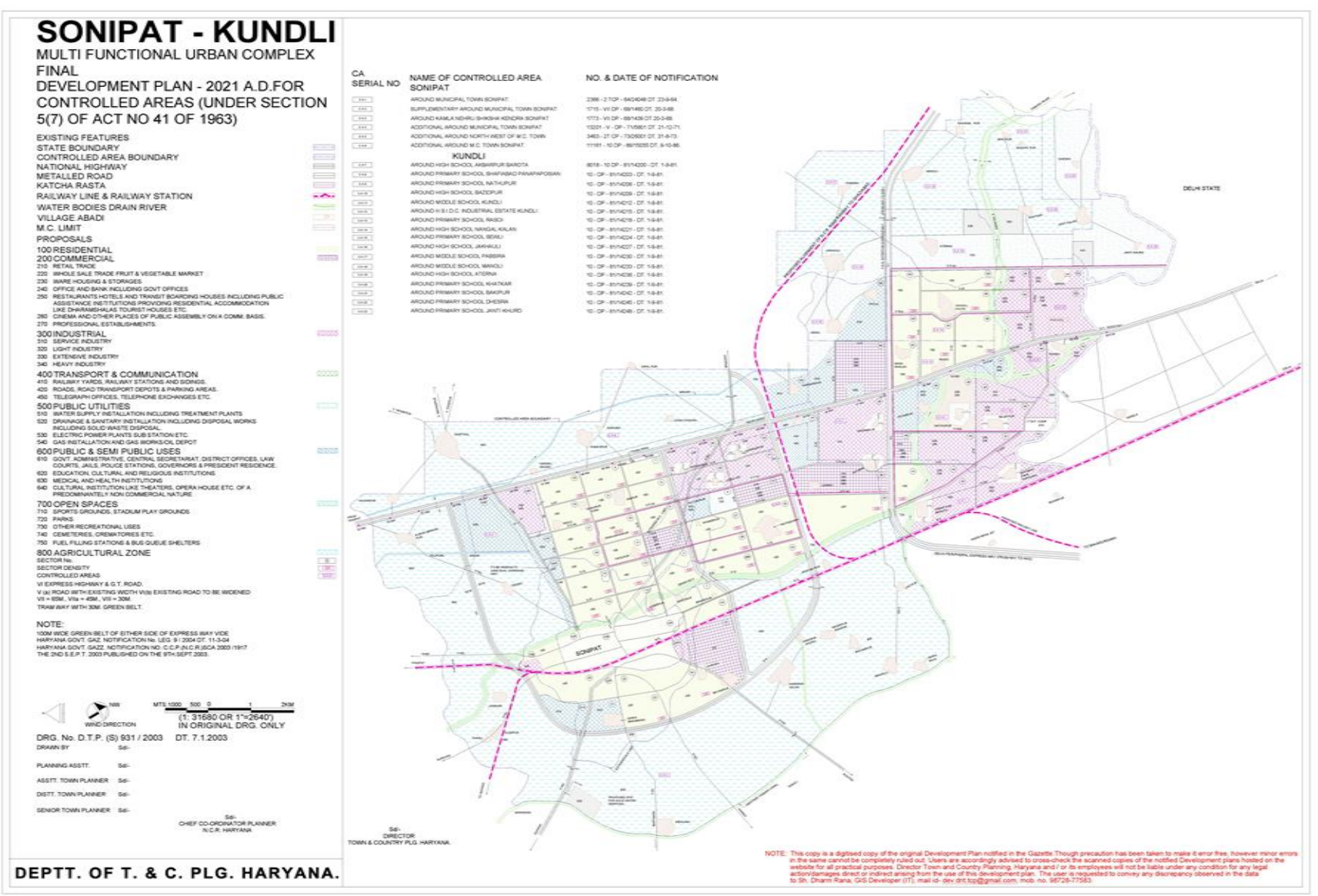

Figure 3. Final Development Plan: Sonipat-Kundli District, Haryana, India.

Image source: Department of Town and Country Planning. "Final Development Plan: Sonipat-Kundli Multi Functional Urban Complex 2021." Haryana: Government of Haryana, 2019. https://tcpharyana.gov.in/Development_Plan/ColouredCopy/SONIPAT_FDP_2021.pdf

The selected village, "Dispute Resolution Village X" (whose name has been changed), is demographically and economically a typical village of its region. Situated in the Rai Block of the state of Haryana in North India, the village is about 40 miles north of the border of Delhi and 15 miles from the regional administrative center of Sonipat, and about a 40-minute drive along mostly fairly good roads from JGU (where the researchers are employed). The language of the village is the local dialect of Hindi and it is entirely Hindu in religious composition, with no Muslims, Sikhs, Christians, or Jains, despite the fact that Haryana was formerly part of the much larger state of Punjab - approximately half of which now lies across the political border in what is (since Partition in 1947) Pakistan.

Dispute Resolution Village X has a population of 3,005, of which 1,637 are male and 1,368 female, divided between 589 households. It has a higher literacy rate than average for rural Haryana (78.29\% v. a state average of 75.55\%), and the literacy rate among the male population is $82.2 \%$ and among women $69.02 \%$. In the age group 0-6 years there are 449 boys and just 259 girls, suggesting, whether through legal or illegal means, a certain degree of sex selection at work. It has two schools-a government one from primary to middle school, and a private school.

The economy of Dispute Resolution Village $\mathrm{X}$ is almost entirely agricultural, with virtually the whole population being engaged in farming of some kind. Exceptions to this are the few local shops stocking general and dry goods, a tea shop, two selling construction materials (e.g., cement, etc.), a pharmacy, a tiny one-room branch of the Punjab National Bank, a rural credit bank, and the local teachers in the schools - specifically in the Anganwadi or preschool groups, of which there are two. These are attended by some small children, in part because attendance guarantees both a free midday meal under the government school meal scheme and periodic visits from accredited social health activist (ASHA) workers. Only 14 of the males in the village and no women reported being engaged in any form of household industry. 
The agricultural economy of Dispute Resolution Village $\mathrm{X}$ is a thriving one, and the village is considered something of a model that has in the past been visited by agricultural experts from Israel and other foreign countries. Almost all households have at least one cow, and the cultivation includes rice (Central Haryana still being within the rice growing belt before it shades into the wheat belt in northern Haryana and Punjab), peppers, baby corn, and, very importantly, mushrooms. The latter are grown in climate-controlled sheds in compost produced on site, where they are also packed and wrapped. These are exported to Delhi, Sonipat, and in some cases even further afield. They are high value added, and the mushroom cultivation also provides work for landless laborers or those whose cultivable land area is too small to support them or their families.

The village is physically accessible with tarred or paved roads connecting to neighboring villages and across country to Sonipat and to the famous National Highway 1 (or "Grand Trunk Road"), which links Delhi with Chandigarh and points north. The highway once ran from Calcutta (now Kolkata) in Bengal to Lahore (now in Pakistan), and now gives access to the great vegetable and fruit wholesale market at Azadpur in North Delhi, which is the daily destination of streams of trucks coming from as far away as Kashmir. In terms of infrastructure, Dispute Resolution Village X is reasonably well off, having tap water, landlines and mobile phone coverage, an infrequent bus service, power supply for both domestic and agricultural use, (as noted) two schools and two preschool groups, as well as visitation by both ASHA workers on a regular basis and regular (but short) visits from a special needs peripatetic teacher. The village receives daily newspapers in Hindi and has both a women's selfhelp group, or Mahila Sanghatan, and an agricultural association, or Bharatiya Kisan Sangh, led by one of the village elders.

Conversely, it has no regular market, no Internet café or common Internet service center, and no community toilets. Dispute Resolution Village X is still heavily structured by caste, being dominated by Rajputs, other castes, and Scheduled Tribes being mainly Jats in the former case. Currently, Scheduled Castes (SCs) comprise 10\% of the population (368 individuals: 194 men and 174 women), mostly working as agricultural laborers. In 2011, the date of the last national census, there was no resident doctor or pharmacy in the village. A severe outbreak of dengue fever in 2015 is credited locally with the subsequent opening of a small clinic with a qualified medical practitioner, and the opening of two small pharmacies that now stock essential medicines. Also initiated was a village-wide campaign to clean up trash and polluted water bodies, and to generally improve the sanitation of the village. In 2011, there was not even a traditional medical practitioner of any kind in Dispute Resolution Village $\mathrm{X}$, and it is some distance to a hospital in Sonipat or along the main highway leading to Delhi. ${ }^{33}$

\section{The Villagers Say "Nahin"}

The key question of the research was the penetration and usage of ADR in village contexts. Here the evidence is overwhelmingly negative, but for several discreet reasons. The first of these was simply ignorance of the availability of any such systems, particularly online ones. No villagers had heard of such possibilities or were aware of any attempts by the local government or other agencies to promote such knowledge. No publicity had ever reached the village, and this is, as noted, a fairly accessible, literate, and affluent one, not far from the national capital and with four universities within a 20-25-mile radius. The "backstory" to this ignorance is what might be termed the folklore of the law in rural India. Indian courts are notoriously slow in processing cases, and, incidentally, at the time of the research a new system was unveiled by the national law ministry to allow litigants to track online the progress of their cases through the courts. Although, again, there seems to be little awareness of this possibility, as with ADR.

There is a famous Indian saying — “don't know the law, know the judge" - that does rather accurately reflect the general rural attitude to litigation through the courts. Since most rural people neither know the judge or have the financial means to engage lawyers and pay bribes, nor even understand the language in which their case is to be heard, there is great wariness of becoming involved in litigation. This, one would expect, would make ADR attractive, were it known to be a possibility. Yet, this runs up against the second major negativity - the technological one.

While mobile phone usage is almost universal in Dispute Resolution Village X, computer usage is not. There is no broadband access and few computers exist - the exceptions being at the tiny one-room Punjab National Bank branch, the farmers' association where a primitive machine is mostly used to check commodity prices in the local and national markets, and the rural credit association. The two schools have been attempting to introduce computer education but have been restricted both by the price of machines (as a proportion of their small budgets is for materials and equipment) and lack of access to broadband. Even the government school principal had no computer and all records were kept by hand. A high percentage of mobile usage was confined to talking and texting, with little access to the huge potential resources that the technology enables. Almost no women and very few men had any knowledge of how to use a computer, or if they did, beyond the most basic functions, ones that they performed in any case on their phones.

\footnotetext{
${ }^{33}$ Directorate of Census Operations, Census of India 2011.
} 
The third, and sociologically very important, factor was, as in any Indian village, an established means of dispute resolution and one familiar to all villagers. This, in essence, is the existence of the Panchayat, the lowest formal level of governance in India. The Panchayat is perhaps best described as the village council or assembly, a proportion of the members of whom have, by law, to be women. It is the place in principle where decisions relating to the village are debated and resolved and embodied in practical decisions. The literature on the Panchayat system is large, but representative examples include Mathew ${ }^{34}$ and Batakrishnan. ${ }^{35}$ Panchayats are elected bodies, so again in principle it reflects democratic processes. The actuality, as widely known from other village studies in India, is far from this ideal picture in very many cases. Women may physically constitute half the Panchayat, but this does not mean that, especially in a highly patriarchal society such as that of rural Haryana, they are not being manipulated by their menfolk and essentially told how to vote and for what or whom to vote. Dispute Resolution Village X also clearly demonstrates another common issue - that in practice the Panchayat is actually managed by a small group of elderly men, the so-called Khap Panchayat, who dominate it and make most of the significant decisions. Women are excluded from this inner cabinet, and junior men, even if regularly re-elected to a seat on the Panchayat, will have to wait a very long time before achieving the seniority (and local influence) necessary to enter this exclusive group. Caste too plays a role, and the dominant castes in the village tend overwhelmingly to only elect members of their own community, leaving tribal and members of lower or excluded castes outside of the decision-making process. Of course, they also tend to make decisions that favor the interests of their own caste. As noted, the dominant caste in Dispute Resolution Village X are Rajputs, once a major and powerful caste spread over much of North India, from Rajasthan to the west to Uttar Pradesh to the east.

In a relatively short period of fieldwork, it was not possible to track all inter- and intra-village disputes, but a reasonable sample was gained from interviews with individual villagers, examination of Panchayat records and meeting minutes, listening into local gossip at the teahouse, discussion with the current Panchayat head, and meetings with the manager (and sole employee) of the tiny village bank. From these sources a fairly consistent profile emerged. Not surprisingly in an overwhelmingly agricultural community, most disputes involved in some form or another land. These comprised disputes over ownership (few since field boundaries and other such matters had mostly long been resolved), access (e.g., grazing of animals), water rights (important in an area where agriculture is essentially rain-fed, with supplementary water coming from borewells), complaints about pesticide spraying in fields adjacent to ones in which other farmers were attempting to establish organic crops, and fair access to shared agricultural machinery.

A second category concerned wages and labor issues, mostly involving occasional migrant labor (mainly from neighboring Uttar Pradesh or from Bihar or occasionally Rajasthan), Adivasi or Scheduled Tribes members (of whom 368 resided within the administrative boundaries of the village), or landless laborers (of whom only 34 were identified: 25 males and nine females). This small figure points to the fact that almost all land in Dispute Resolution Village $\mathrm{X}$ is owned by its cultivators. Large landlords do not exist, but the renting of small amounts of land, mainly for vegetable production for home consumption, does occur. Meanwhile, the third category involved family disputes over inheritance, property, marriage, divorce, and custody.

The final, and rare category, were disputes involving bodies beyond the village, such as consumer complaints, taxation, the maintaining of public roads, and compensation for compulsory land acquisition for public works, drains, mobile network towers, and the like. In fact, it might not be accurate to call these issues "disputes" at all, as they mainly involve negotiations, queries, and low-level disagreements about such familiar matters as tax, and which have fairly clearly laid out bureaucratic procedures for their resolution. Although, as with the legal system, these procedures are not always carried out according to the formal rules, but often involve influence, corruption, and similar practices to bypass or speed up bureaucratic processes.

In practice, it was evident from Panchayat records that almost all disputes involving the first three categories were handled "in house" as it were, through mediation of the village elders and, where necessary, the imposition of small fines or other penalties by the Panchayat on deviant members of the community. Crime as such seemed to be virtually absent, the size of the community and the fact that everyone knows everyone else ensuring high levels of mutual surveillance.

The final category rarely involved lawyers but occasionally involved travel to Sonipat to the mini secretariat in the town, which contains the offices of the district magistrate, the police chief, the local court, and the various bureaucratic agencies responsible for local administration. Elsewhere in the town are the tax offices, local branches of the agriculture ministry, the education department (responsible for the village public school), and other government bodies rarely visited but occasionally needed for permissions and licenses (e.g., for the establishment and monitoring for health and safety reasons of the mushroom cultivation establishments or the large polytunnels used in sweet corn, tomato, and capsicum cultivation).

\footnotetext{
${ }^{34}$ Mathew, Panchayati Raj.

${ }^{35}$ Balakrishnan, Participatory Pathways.
} 
Previous studies of ADR and ODR ${ }^{36} 37$ have shown that (including in India, where it exists) it has been largely applied to trade disputes, disputes over online transactions and purchasing, technology-related issues, and in the context of urban, international, and corporate situations. Certainly, attention has been drawn to the cultural dimensions of ADR, including the role of kinship networks, traditional dispute-resolution mechanisms, and lack of exposure to alternative possibilities outside of well-established traditional procedures and social structures. ${ }^{38}$ The Dispute Resolution Village X case study underlines a number of these dimensions in addition to lack of technology and similar objective factors, including that the existence of such mechanisms is simply unknown. In fact, it underlines a number of key dimensions that relate to the adaptation of ADRs in village contexts in India and no doubt elsewhere. The two major factors, other than lack of access to the necessary technology, are, first, the existence of established and culturally acceptable dispute-resolution mechanisms, and second, the nature of the disputes that arise to be solved. These are almost all very local in nature and are addressed in the context of local land tenure, caste, ecological, and political conditions, which have not varied much over long periods of time. The avoidance of formal legal routes is, thus, very well established, and the courts, given the high levels of corruption and the often interminable time frame of litigation, are not held in high esteem.

This is reinforced by the fact that in the rural context little or nothing has been done to publicize the existence of cheap and less time-consuming alternatives than the traditional legal channels. Lack of penetration, lack of technology, and unfamiliarity with online ADR processes, together with well-established and well-understood dispute-resolution mechanisms, largely completes the picture. If this is true of a relatively affluent village such as Dispute Resolution Village X, not too far from major and regional urban centers, it is hardly surprising that ADR has not penetrated at all into very interior villages, many with only at best intermittent electricity supply, and with low levels of general literacy, to say nothing of computer literacy.

\section{Conclusion}

Does this mean that ODR in rural India is effectively a failure even before it has begun? There are signs that this may not be true for a number of reasons. An obvious one is the spread of computer literacy among younger Indians, India being a major exporter of software engineers and other IT experts to much of the world. This is reinforced by the exponentially growing capacity of mobile phones. Given the high level of mobile phone ownership and use in rural India and the fact that large and growing areas of the country are within range of reception towers, computer ownership is no longer a prerequisite for accessing numerous online functions. However, the mobile phone, despite its many functions, has its limitations. ODR cannot be accessed by SMS other than exchanging simple messages, and no "apps" have been developed to do so. Yet, even that suggests that a potential litigant would be so keen on the idea that they would want such a semi-permanent application on their phone. Given the caste-ridden and gendered nature of Indian rural society, justice is certainly not always done or seen to be done to members of tribal communities, backward castes, women, and other excluded groups, precisely because of the potentially or actually biased nature of traditional governance and dispute-resolution mechanisms. As endless cases from all over India graphically show, it is particularly hard for a Dalit (an "untouchable"), for example, to win a local case against a Brahmin (a member of the highest caste in the traditional hierarchy), and even if he or she does, harassment and other forms of persecution are likely to follow.

While Dispute Resolution Village X is composed largely of Rajput caste members and backward castes are not well represented, local Jats have been-unsuccessfully-lobbying to have themselves reclassified as "Other Backward Castes" to access privileges reserved for such castes as government posts, scholarships, and other benefits. However, discussion with such tribal, SCs, and Other Backward Castes who do exist in the village suggest that when informed about the existence of ADR, they were in principle keen on it, precisely because - and this was the case with female informants of all castes - it would enable them to bypass the biased traditional mechanisms and go directly and personally to a method that they believed had the potential to deliver much faster and uncorrupted solutions to their legal needs. This is perhaps one of the key areas in which the potential of ADR in rural India can be realized - that is, as a form of social justice not trapped within the still rigid sociological and cultural boundaries of traditional mechanisms.

This article suggests that for the above-mentioned reasons a desire to utilize new online ADR methods either with existing village ADR methods (online Lok Adalat) or via completely new methods (online mediation or conciliation) previously unknown to the villagers has not yet occurred across the entire village, but some villagers may in principle be interested in online ADR. This is particularly true for women, whose voices carry much less weight in the Panchayat and whose genuine interests are likely to become distorted under the pressure of what is locally widely accepted as being a highly patriarchal social system.

\footnotetext{
${ }^{36}$ Bharadwaj, "ADR in Consumer Protection."

${ }^{37}$ Leigh, "Online Dispute Resolution."

${ }^{38}$ Gold, "ADR Through a Cultural Lens."
} 
We believe this is partly for reasons of awareness and limited Internet access, and partly because of existing power structures in the village that frustrate change. To promote increased use of online ADR, providers might want to consider generating a sense of ownership among the existing village elders, outlining the benefits of online ADR (potentially quicker, confidential, and more impartial), and providing training through NGOs to women, youth, and other groups likely to benefit from its use. In addition, outsiders, including well-meaning legal authorities and local government officials, may need to anticipate resistance to new ways of doing things in light of the existing village power structures.

The policy recommendations that arise from this study to support the spread of ADR (and by extension online ADR) include culturally appropriate awareness campaigns in Hindi and local languages, educational campaigns through schools and NGOs, the use of local role models such as actors and sports personalities, and other methods to "normalize" ODR as a rational choice and not a curiosity. Mobile phone-based apps might be far more applicable than having access to laptops in the village context. In addition, recent trends in holo-conferencing might be too much of a culture shock if introduced too quickly. While online video games and streaming of movies is common, especially among younger villagers (most of whom are also very familiar with social media applications), there is no evidence of this having any effect on potential use of ADR mechanisms. Technology appears to be driving ADR. ${ }^{39}$

As our villagers were unaware of the existence of online ADR mechanisms or efforts to promote online ADR by the local government, they were also unaware of the legal enforceability of successful online ADR mechanisms, assurance of confidentiality, and the advantages of online ADR compared to traditional methods, including what ADR methods were available to them, such as mediation, arbitration, and conciliation. We also note that almost $50 \%$ of Indian lawyers are estimated to hold fake qualifications, ${ }^{40}$ so the question of who facilitates and runs the online ADR may also arise, as well as other questions about costs, trust, and confidentiality.

While traditional Panchayat ADR or Lok Adalat may resolve a dispute, our research was not able to assess the success rate of enforcing such agreements or how confidential they remain in a rural village setting among the villagers themselves. We could neither verify what constitutes a satisfactory resolution in many cases - a compromise or a clear decision in the interests of one of the disputing parties?

Incorporation of online ADR into existing ADR formats already accepted at the village level (such as mobile Lok Adalats) may help if the mobile Lok Adalats were conducted via the Internet or using smartphones. This makes the Lok Adalat more accessible to villagers at the rural level in a culturally acceptable framework, and further reduces existing delays through Lok Adalats conducted through traditional means.

Recommendations also include improving efficiency of ADR, reducing delay, ensuring a supportive judiciary, increasing ADR training, ensuring arbitrator accountability, increasing awareness of ADR, changing the mindset of stakeholders, ${ }^{41}$ and performing street plays in the local dialect. ${ }^{42}$ Indeed, this has been done in many areas of rural India to raise awareness of both dangers (e.g., AIDS) and new possibilities (in such areas as agriculture, local energy systems, and water harvesting).

We note too that any acceptable online ADR program would need to identify village stakeholders, conduct a sociopolitical analysis to be sensitive to questions of gender, caste, class, and power, and be introduced gradually so that the villagers can form a consensus on incorporating new technology into their existing ADR methods without causing social upheaval by subverting time-honored dispute-resolution methods. Such methods could perhaps be adapted or used as the basis for education in the potential of online ADR, and further utilized as a bridge to efficient and technologically enabled forms of dispute resolution that do not simply reproduce the delays and corruption of much of the existing court system in India.

We also argue that the case study, modest as it is and restricted to a single village, has significant theoretical implications. Rebecca Sandefor in a discussion of access to justice in the North American context makes an important distinction between what she terms "justice problems" and "legal problems," the latter usually requiring access to formal legal processes, but the former also utilizing a range of possibilities from "do-it-yourself" divorce or property conveyancing, through arbitration, to procedures as simple as writing one's own letters of complaint. On the basis of US data, she concludes that "[m]ost civil justice problems are handled by people on their own, or with advice from family and friends," 43 since "[r] esolving justice problems lawfully does not always require lawyers' assistance." 44 In fact, she even argues the stronger case that the existing legal system

\footnotetext{
39 Alexander, "Mobile Mediation."

40 Garg, "Indian Lawyers."

${ }^{41}$ Muhamad, Alternative Dispute Resolution.

42 Sharma, "Strengthen ADR in India."

43 Sandefor, "Access to What?" 51.

44 Sandefor, “Access to What?" 49.
} 
is largely designed by lawyers and substantially in their own interests, and that accordingly it is important to ensure that the legal profession does not monopolize the justice system. ${ }^{45}$ While certainly knowing how to access and navigate any ADR system may well require the help and advice of a legal professional, these need not necessarily be lawyers. At the time of writing, the Jindal Global Law School at JGU had just announced the launch of a new degree in paralegal studies, shorter than the professional law degree and aimed precisely at those desiring a legal education without becoming fully fledged lawyers. Sandefor's other major point is that it is largely through social networks that disputes are resolved, not through any formal legal process, with its likely costs, delays, and (to the layperson) unintelligible terminology.

ADR in its various forms hovers at a sort of intermediate point here between the formal court system and informal and selfhelp. It also offers itself - certainly in the Indian context, when a "justice problem" does seem to require some recourse to the legal sphere - as a potential mediating mechanism. However, as the case study has shown, cultural and social structural restraints play a very large part in the resolution of what are locally conceived of as "justice problems" rather than as "legal problems." This brings us to our final theoretical point. Reza Banaker and others have argued persuasively that the notion of rights is a complex and contested one when placed in a comparative cultural context. Normative claims phrased in terms of a language of rights may in fact be rare: in practice, social structures and existing interest and relationships may prove to be far more salient. ${ }^{46}$ While agreeing that contemporary society is in many ways "liquid" and that the social relationships and structures of what he calls "early modernity" are in transition globally (and certainly in India), it is not correct to assume "that 'liquid society' provides an adequate description of the present society where many social institutions retain their apparent 'solidity' and durability.",47

Our case study suggests that he is right on both counts - that disputes in rural India are not necessarily or frequently phrased in terms of a rights discourse, and that the power of culture and social structure persists despite, or even in opposition to, "modernity." It can be said with some confidence that the average Indian village is a very socially conservative place. The social mechanisms of "persuasion, appeals to conscience, 'naming and shaming' and threats of exclusion" that Banaker cites as examples of this are exactly what were discovered and perhaps anticipated in Dispute Resolution Village X. He also identifies an important element often missing in rights discourse, notably its relationship (or lack of relationship) to the moral sphere. This we feel is correct: discourses of rights in Dispute Resolution Village X are largely debated in moral terms. Yet, we also differ from Banakar on one important point. He argues that:

moral issues are increasingly juridified and expressed in terms of legal rights and codes of conduct. This process of juridification marginalizes moral concerns in public political discourse, thus relieving citizenry and authorities of the burden of debating the morally intricate and socially complex dimensions of harmful actions and events that are born out of structural inequities in late modern societies. ${ }^{48}$

This we contest on the twofold grounds that it is not true within the village, where "moral" discourse is the medium of debate framed within the context of local culture, religion, and social structure (very much including caste), but does reflect the "negotiation" of spheres that villagers must reckon with when they leave the boundaries of their own moral sphere and enter into the formal juridical system outside. This space might share some of their cultural assumptions, but it also operates according to much more "abstract" principles and procedures the further they enter into the realm of "legal problems."

Indeed, taking a more sociological approach, Smith argues that a rights discourse leads to what he calls the "colonization" of morality, which happens when rights "become dislocated from a sense of responsibility for others." 49 In this article we have attempted to illustrate resistance to this "colonization" in a North Indian village and the persistence of social structure in the face of modernity, while placing that resistance in a complex dialectic with the penetration of new technologies of communication. At the same time, we debate both the salience of ADR as a potential tool for access to justice in rural communities, and explore the barriers to that happening in terms of both technological enablement and sociocultural norms.

\footnotetext{
${ }^{45}$ Sandefor, "Access to What?" 54.

${ }^{46}$ Banakar, "Law, Rights and Justice."

${ }^{47}$ Banakar, "Law, Rights and Justice."

${ }^{48}$ Banakar, "Law, Rights and Justice," 3.

${ }^{49}$ Smith, "Sequestration," 45.
} 


\section{Bibliography}

Alexander, Nadja. "Mobile Mediation: How Technology is Driving the Globalization of ADR." Hamline Journal of Public Law and Policy 27, no 2 (2006): 243-262.

Balakrishnan Rajiv (ed.). Participatory Pathways: People's Participation in Development Initiatives. New Delhi: Pearson Education India, 2007.

Banakar, Reza. "Law, Rights and Justice in Late Modern Society: A Tentative Theoretical Framework." In Rights in Context: Law and Justice in Late Modern Society, edited by Reza Banakar, 1-18. Farnham: Ashgate, 2010.

Bharadwaj, Krishna. "A Critical Study on the Role of ADR in Consumer Protection in India." National Conference on Consumer Protection, Kaamadhenu Arts and Science College, Erode District, Tamil Nadu, 2017.

Cybersettle. Accessed April 26, 2020. http://www.cybersettle.com/.

Directorate of Census Operations. Census of India 2011: District Census Handbook Sonipat, Part XII-B. Haryana: Government Printer, 2011.

Evans-Pritchard, Edward Evan. Witchcraft, Oracles and Magic Among the Azande. Oxford: Clarendon Press, 1937. - The Nuer: A Description of the Modes of Livelihood and Political Institutions of a Nilotic People. Oxford: Clarendon Press, 1940.

Garg, Abhinav. "Almost Half of All Indian Lawyers Are Fake, Bar Council of India Claims.” India Times, January 23, 2017. https://www.indiatimes.com/news/india/almost-half-of-all-indian-lawyers-are-fake-bar-council-of-india-claims270056.html.

Gold, Julia Ann. “ADR Through a Cultural Lens: How Cultural Values Shape Our Disputing Process.” Journal of Dispute Resolution 2005, no 2 (2005): 1-321.

Goodman, Joseph W. "The Pros and Cons of Online Dispute Resolution: An Assessment of Cyber-Mediation Websites." Duke Law \& Technology Review 2 (2003): 1-16.

Indian Department of Justice. Online Dispute Resolution Through Mediation, Arbitration, Conciliation, Etc. (Government of India, n.d.).

Indian Economic Service. “Gram Nyayalayas or Village Courts.” Last modified March 13, 2015. http://www.arthapedia.in/index.php?title=Gram_Nyayalayas_or_Village_Courts.

Indo-Asian News Service. "Around 67 Per Cent of Internet Users in India Are Male, Claims Report.” India Today, September 28, 2019. https://www.indiatoday.in/technology/news/story/around-67-per-cent-of-internet-users-in-india-aremale-claims-report-1603535-2019-09-26.

Internet and Mobile Association of India. 2017 Mobile Internet Report (Kantar IMRB, 2017).

Khatria, Bhumika. “Is India Reaching the Saturation Point for New Mobile Subscribers?” Inc42, May 31, 2019. https://inc42.com/features/has-india-reached-a-ceiling-point-of-new-mobile-users/.

Kumar, Chockalingam Raj. "Arbitration, Mediation and Conciliation: Can the COVID-19 Crisis Reimagine the ADR Regime?” O. P. Jindal Global University, June 13, 2020. Facebook webinar, 1:39:40. https://www.facebook.com/589909274416608/videos/263053141677042/.

Legal Referee. "Services: Arbitration.” Accessed April 26, 2020. http://legalreferee.com/services/.

Leigh, Doug and Frank Fowlie. "Online Dispute Resolution (ODR) within Developing Nations: A Qualitative Evaluation of Transfer and Impact." Laws 3, no 1 (2014): 106-116. https://doi.org/10.3390/laws3010106.

Llewellyn, Karl N. and E. Adamson Hoebel. The Cheyenne Way: Conflict and Case Law in Primitive Jurisprudence. Norman: University of Oklahoma Press, 1941.

Mandavia, Megha. "India Has Second Highest Number of Internet Users after China: Report." The Economic Times, September 26, 2019. https://economictimes.indiatimes.com/tech/internet/india-has-second-highest-number-of-internetusers-after-china-report/articleshow/71311705.cms.

Mathew, George (ed.). Status of Panchayati Raj in the States and Union Territories of India. New Delhi: Institute of Social Sciences, 2000.

Muhamad, Malik S. Alternative Dispute Resolution in India and the United States: A Comparative Analysis and Recommendations to Improve Efficiency and Effectiveness in Indian ADR (Cornell University, 2018).

Nair, Harish. "3.3 Crore Backlog Cases in Courts, Pendency Figure at Highest: CJI Dipak Misra." India Today, June 28, 2018. https://www.indiatoday.in/india/story/3-3-crore-backlog-cases-in-courts-pendency-figure-at-highest-cji-dipakmisra-1271752-2018-06-28.

Nairan, Rashika and Abhinav Sankaranarayanan. "Formulating a Model Legislative Framework for Mediation in India." NUJS Law Review 11, no 1 (2018): 75-120.

National Law School of India. "Online Consumer Mediation Centre.” Accessed April 26, 2020. https://onlinemediationcenter.ac.in/.

National Legal Services Authority. "Lok Adalat." Accessed April 26, 2020. https://nalsa.gov.in/lok-adalat.

National Portal of India. "Alternative Dispute Redressal (ADR)." Last modified November 26, 2019.

https://www.india.gov.in/topics/law-justice/alternative-dispute-redressal-adr. 
Negi, Chitranjali. Concept \& Overview of Online Arbitration (January 14, 2016). http://dx.doi.org/10.2139/ssrn.2715684.

Pahwa, Gunita. "Making India an Arbitration Hub." Financial Express, September 5, 2019. https://www.financialexpress.com/opinion/making-india-an-arbitration-hub/1696506/.

Press Trust of India. “India Has 19 Judges per 10 Lakh People: Data.” The Economic Times, September 24, 2018. https://economictimes.indiatimes.com/news/politics-and-nation/india-has-19-judges-per-10-lakh-peopledata/articleshow/65935214.cms.

Roberts, Simon. Order and Dispute: An Introduction to Legal Anthropology. 2nd edition. London: Penguin, 2016.

Rodrigues, Jonathan. "Reintroducing Mediation to Millennial India.” International Mediation Institute, August $22,2019$. https://www.imimediation.org/2019/08/22/reintroducing-mediation-to-millennial-india/.

Sama. "Make Space for Resolution.” Accessed April 26, 2020. https://www.sama.live/.

Sandefor, Rebecca L. “Access to What?” Daedalus 148, no 1 (2019): 49-55. https://doi.org/10.1162/DAED_a_00534.

Sharma, Bhumika. "Suggestive Measure to Strengthen ADR in India." Indian National Bar Association. https://www.indianbarassociation.org/suggestive-measure-to-strengthen-adr-in-india/.

Singh, Shipra. "Here's How Consumers will Benefit under the New Consumer Protection Act." The Economic Times, August 19, 2019. https://economictimes.indiatimes.com/wealth/spend/heres-how-consumers-will-benefit-under-the-newconsumer-protection-act/articleshow/70711304.cms?from=mdr.

Smith, Carole. "The Sequestration of Experience: Rights, Talk and Moral Thinking in 'Late Modernity'.” Sociology 36, no 1 (2002): 43-66. https://doi.org/10.1177/0038038502036001003.

Student Judicial Association. "NUJS Startup ODRways Will Lead the First E-ADR Institution of India." National University of Juridical Science, Kolkata, April 7, 2019. https://sja.nujs.edu/newsroom/2019/04/07/nujs-startup-odrways-will-leadthe-first-e-adr-institution-of-india.

The Telegraph. "CJI Focus on Speedy End to Litigation.” December 8, 2019. https://www.telegraphindia.com/india/cjibobde-focuses-on-speedy-end-to-litigation/cid/1725051.

Vazifdar, Shiavax Jal. “Foreword.” In Alternative Dispute Resolution Mechanisms (Haryana State Legal Services Authority Haryana, India, n.d.).

World Intellectual Property Organization. “ADR Advantages.” Accessed April 26, 2020. https://www.wipo.int/amc/en/center/advantages.html.

\section{Primary Legal Material}

Arbitration and Conciliation Act 1996.

Arbitration and Conciliation (Amendment) Act 2019.

Bharat Aluminium Co v. Kaiser Aluminium Technical (2012) 9 SCC 552.

Bhatia International v. Bulk Trading SA (2002) 4 SCC 105.

Consumer Protection Act 2019.

Guru Nanak Foundation v. Rattan Singh \& Sons (1981) AIR 2075, (1982) SCR (1) 842.

Hindu Marriage Act 1955.

Information Technology Act 2000. 